\title{
A GERONTOLOGIA E A INTERDISCIPLINARIDADE: ASPECTOS RELEVANTES PARA A ENFERMAGEM
}

\author{
Alessandra Conceição Leite Funchal Camacho ${ }^{1}$
}

Camacho ACLF. A gerontologia e a interdisciplinaridade: aspectos relevantes para a enfermagem. Rev Latino-am Enfermagem 2002 marçoabril; 10(2):229-33.

Este artigo retrata a Gerontologia como área rica e cheia de lacunas a serem preenchidas pelas disciplinas que a compõem, indo além das abordagens convencionais à clientela idosa, visando a caminhos renovados para a Enfermagem, que, dentre tantas disciplinas, também está no processo construtivo de conhecimento. Tem como objetivo destacar a importância da Gerontologia para a atuação interdisciplinar, principalmente para Enfermagem, ressaltando o cliente idoso no contexto social. A interdisciplinaridade é instrumento condutor para Gerontologia em busca de mudanças que venham a somar conhecimentos e redundar em esforços no processo de desenvolvimento da área da saúde em relação ao cliente idoso e às diversas disciplinas que contemplam uma atuação relevante que, sem dúvida, permitem avanços para a Enfermagem.

DESCRITORES: gerontologia, enfermagem

\section{GERONTOLOGY AND INTERDISCIPLINARITY: RELEVANT ASPECTS TO NURSING}

This article shows Gerontology as a rich area and full of gaps to be filled by the disciplines that form it, going beyond the conventional approaches to the elderly client and aiming at finding new Nursing paths as, among other sciences, it is in the process of knowledge building. The study aims at emphasizing the importance of Gerontology in an interdisciplinary context, specially for Nursing, as well as the relevance of the elderly client in the social context. The interdisciplinarity is the Gerontology guiding tool in the search for changes that may sum-up knowledge and efforts in the process of health development regarding the elderly clients and other disciplines, enabling Nursing advancement.

DESCRIPTORS: gerontology, nursing

\section{LA GERONTOLOGÍA E INTERDISCIPLINARIDADE: LOS ASPECTOS RELEVANTES PARA LA ENFERMERÍA}

Este artículo retrata la Gerontología como área rica y llena de lagunas para ser resueltas por las disciplinas que la componen, yendo más allá de los abordajes convencionales a la población anciana, buscando caminos renovados para enfermería, que dentro de tantas disciplinas, también está en el proceso constructivo del conocimiento. Tiene como objetivo destacar la importancia de la gerontología para la actuación interdisciplinaria, principalmente para enfermería, resaltando al paciente anciano en el contexto social. La interdisciplinariedad La interdisciplinariedad es instrumento conductor para la Gerontología en busca de cambios que vengan a agregar conocimientos que redunden en esfuerzos para el proceso de desarrollo del área de la salud en relación con el cliente anciano, y las diversas disciplinas que contemplan una actuación relevante que, sin duda, permitan avances para enfermería.

DESCRIPTORES: gerontología, enfermería

\footnotetext{
${ }^{1}$ Enfermeira, Professor da Faculdade de Enfermagem da Universidade Estácio de Sá. Chefe de Enfermagem do Centro de Doença de Alzheimer - IPUB da Universidade Federal do Rio de Janeiro, Mestranda em Enfermagem pela Escola de Enfermagem Anna Nery da Universidade Federal do Rio de Janeiro, Endereço: Rua: Torres Homem, 1114 - Ap. 801 - Vila Isabel - 20551-070 - Rio de Janeiro - RJ - Brasil
} 
INTRODUÇÃO

O velho, o idoso ou a pessoa da terceira idade* compreendem, atualmente, uma clientela socialmente importante, na qual se estabelecem diversos enfoques que não se restringem apenas a uma área de conhecimento, mas a várias possibilidades a serem desvendadas sobre essa clientela ${ }^{(1)}$.

Assistimos $^{(2)}$ a uma socialização progressiva da gestão da velhice, considerada, durante alguns anos, própria da esfera privada e familiar, ligada a movimentos filantrópicos, mas que, atualmente, torna-se um assunto público e amplamente discutido. 0 que se observa são intervenções governamentais implementadas de forma contraditória, que acabam por ordenar o saber específico da Gerontologia, desenvolvido por profissionais e instituições especializadas no envelhecimento. Nessa disposição, surge, assim, uma categoria culturalmente produzida, ou seja, os idosos.

A velhice possui características próprias de sua estrutura social, o que nos coloca como sujeitos e agentes da saúde, abrindo espaços e novas experiências a serem vivenciadas, pois levamos em consideração o envelhecimento com múltiplas dimensões que abrangem questões de ordem social, política, cultural e econômica.

Isso se justifica pela impossibilidade de estabelecer conceitos e terminologias amplamente aceitáveis em relação ao envelhecimento, o que depende das políticas e ideologias associadas a determinadas sociedades. Do ponto de vista cultural, percebe-se, de maneira diferenciada, como, por exemplo, em cidades, onde algumas pessoas vivem em favelas, que a velhice tem uma conotação distinta em comparação àquelas cidades com serviços de saúde e moradia adequada ${ }^{(3)}$.

0 que se verifica nessas múltiplas dimensões sobre 0 envelhecimento é a área da Gerontologia em desenvolvimento contínuo, voltada para a longevidade e a qualidade de vida do idoso, com pesquisas pertinentes à área da saúde, ressaltando a independência, estilo de vida, além de abranger demais áreas como a Psicologia, a Sociologia, a Antropologia, entre outras.

É interessante perceber que a Enfermagem Gerontológica destaca-se num processo específico baseado na compreensão de parâmetros físicos, emocionais e de ordem social, pelo qual a atuação da equipe interdisciplinar desmistifica o papel de cada profissional e deixa claras as especificidades de suas funções. É um processo que corre fundamentalmente de forma educativa para todas as partes, em direção à clientela idosa.

Dessa forma, a avaliação funcional do idoso faz parte do cuidado de enfermagem, com ênfase na pessoa e nos sistemas de apoio com os quais possa contar. A Enfermagem inserida numa equipe interdisciplinar deve assistir o idoso de maneira individualizada, levando em consideração as suas limitações físicas, psíquicas e ambientais ${ }^{(4)}$.

Nesse enfoque, a Gerontologia abrange pesquisas científicas direcionadas ao envelhecimento humano, com relevância para as múltiplas áreas que se entrelaçam e preenchem os espaços até então desconhecidos. Tais razões configuram-se no momento em que, na estrutura populacional, são observados aumentos da expectativa de vida, baixa nas taxas de natalidade e mortalidade, continuamente a novos modos de produção econômica e social (grau de desenvolvimento do país e as categorias profissionais de onde provêm os aposentados), além do pleno exercício da cidadania em qualquer fase da vida e em qualquer circunstância.

Nesse sentido, o papel da Gerontologia, em sua constituição, incorpora subsídios técnicos e cientíicos de outros ramos afins que os transcendem. Ao responder a algumas necessidades, a Gerontologia desenvolve um trabalho interdisciplinar em sua gênese, no fundamento da própria produção do saber e da própria ação interventiva ${ }^{(5)}$.

Dessa forma, este texto tem como objetivo ressaltar a importância da Gerontologia como área de conhecimento relevante para a atuação interdisciplinar, bem como a sua pertinência para a Enfermagem, destacando o processo de envelhecimento no contexto social.

\section{O IDOSO E O CONTEXTO SOCIAL}

Dada a atual ênfase no idoso, existe uma grande preocupação e integração dos profissionais de diversas áreas da saúde em relação a esse grupo. Isso surge em decorrência de um processo de transição demográfica e epidemiológica que o Brasil vem mostrando de forma heterogênea, associado, em grande parte, às dificuldades sociais observadas no país. A população idosa constitui-se como um grupo bastante diferenciado entre si e em relação aos demais grupos etários, e, qualquer que seja o enfoque, a situação dessa parcela da população é bastante expressiva.

Tal ênfase é corroborada a partir de dados demográficos, de instituições oficiais de informação e de estudos epidemiológicos ${ }^{(6)}$. Surge, assim, uma preocupação maior com essa camada da população, pois os custos econômicos e sociais decorrentes dela vêm transcendendo as projeções consideradas para esse grupo, numa situação vigente de um sistema de Saúde Pública espoliado ao extremo.

\footnotetext{
* Viabilizei estes três termos por serem amplamente utilizados e possuírem significados simbólicos diferenciados. Idoso simboliza, sobre tudo, as pessoas mais velhas, e também chamados de "velhos respeitados"; a terceira idade corresponde aos "jovens velhos", os aposentados dinâmicos; o "velho" tem uma conotação negativa ao designar as pessoas de mais idade pertencentes às camadas populares ${ }^{(1)}$.
} 
Ainda em relação ao envelhecimento populacional, há a alocação de novas exigências dos serviços de ordem social e de saúde, com onerosas intervenções e tecnologia de alta complexidade. Associa-se, também, o envelhecimento populacional como um dilema, em termos de políticas de saúde no Brasil, sendo que os recursos para os programas sociais deverão combater as doenças crônicas como artrite, cardiopatias, doenças degenerativas, debilidades cognitivas, entre outros males típicos da velhice. Acrescentam-se aos problemas de saúde, os benefícios e pensões da seguridade social a que todo o idoso tem direito ${ }^{(3)}$.

A velhice, em relação à sociedade, é um problema configurado no direito à aposentadoria, com uma renda adquirida por anos de trabalho, e contextualiza-se como um problema de ordem pública. Faço referência ao impacto no sistema da Previdência Social, ao afirmar que 0 envelhecimento transforma-se numa questão de peso para a economia, a vida social e cultural da sociedade. A ampliação das camadas médias e a extensão dos regimes previdenciários a todas as categorias fizeram com que a preocupação com a velhice não se restringisse aos setores empobrecidos ${ }^{(7)}$.

$O$ aposentado é definido nesta posição como um elemento que sofre discriminação, levando à inatividade e a seu retorno a casa, determinando uma troca de papéis simbólicos na estrutura familiar e profissional, submetendo-o a uma sociedade que prega a eficiência, a produção e a estética como valores essenciais.

Por meio de fontes de análise do Instituto Brasileiro de Geografia e Estatística (IBGE) ${ }^{(8)}$, verifica-se que, além da desigualdade socioeconômica, destaca-se a sociabilidade do idoso como um fator importante, pois inclui as relações de convivência familiar, o estabelecimento do vínculo social com a comunidade e a possibilidade real de qualidade de vida e, conseqüentemente, a sua sobrevivência.

Essa postura acaba por familiarizar períodos da vida do homem, como um processo simbolicamente compartilhado com grades etárias estabelecidas (infância, adolescência, fase adulta e a idosa). Portanto, poderia, assim, afirmar que a velhice é uma categoria socialmente produzida ${ }^{(9)}$, pela qual a padronização da infância, da adolescência, da idade adulta e da velhice pode ser entendida como resposta a mudanças estruturais da economia, sobretudo à transição de uma economia que tinha como base a unidade doméstica para uma economia baseada em mercado de trabalho. A regulamentação estatal do curso da vida está presente do nascimento até a morte, passando por um sistema complexo que engloba as fases de escolarização, entrada no mercado de trabalho e aposentadoria.

As relações podem ser compreendidas, ampliadas e até transformadas numa determinada relação dos grupos que se interagem. Indo um pouco além, distingue-se o ser humano por suas singularidades e subjetividades, cujos conceitos referem-se à mesma realidade, mas possuem facetas diversas. Até porque, na evolução do ser humano, vemos que a singularidade chama a atenção para o fato de sermos diferentes; a subjetividade chama a atenção para 0 fato de que nós somos 'os outros', isto é, nós nos constituímos de relações, de experiências que estabelecemos e vamos estabelecendo a cada dia ${ }^{(10)}$.

Ao mesmo tempo, pressupõem-se condições e características próprias para um determinado grupo se relacionar com suas diversidades as quais tendem a levar ao conhecimento da realidade e ao seu entrelaçamento não se reduzindo nem se confrontando, mas vindo a se somar.

O compromisso profissional não pode ser passivo. Ele deve ser dotado de ações e reflexões sobre a realidade. Isso implica valores humanos fundamentados cientificamente. $\mathrm{Na}$ ampliação dessa fundamentação, os conhecimentos em torno do homem tomam corpo e se tornam críticos e reflexivos, a partir de um novo olhar sobre a realidade vivenciada.

No caso da Enfermagem, descrevo categorias encontradas em publicações sobre o conhecimento em fundamentações gerontológica e geriátrica, assistência de enfermagem gerontológica e geriátrica, educação em saúde e formação de recursos humanos e materiais, como fundamental para os profissionais de enfermagem trabalharem em programas de educação e assistência qualificada às pessoas da terceira idade. Essa visão amplia-se ao se dizer que a atuação implementa a Lei 8.842, da Política Nacional do Idoso (PNI), sobre a grande lacuna existente hoje, na rede de apoio comunitário, tanto para os idosos quanto para os seus familiares, com carência de serviços alternativos como o Centro Dia, Hospital Dia, Residência Protegida, entre outras ${ }^{(11)}$.

$\mathrm{Na}$ realidade, o que se observa em alguns trabalhos desenvolvidos por gerontólogos de diversas áreas de conhecimento, são mudanças de discursos com vistas a novos padrões de envelhecimento e experiências cheias de atividades, oportunidades de lazer, além de grupos de convivência, bem como as universidades da terceira idade. Dessa forma, o discurso da improdutividade ainda é visto no mercado de trabalho, organizando-se como um estereótipo que acaba por estigmatizar e até excluir o idoso de seu meio familiar, além de reproduzir comportamentos de alteridade de parentes e amigos como um valor que ainda se reflete nas estruturas de nossa sociedade.

\section{INTERDISCIPLINARIDADE E A GERONTOLOGIA: ASPECTOS RELEVANTES PARA A ENFERMAGEM}

Tendo em vista a Interdisciplinaridade como possibilidade de manifestar ou correlacionar diversos tipos de conhecimentos fragmentados, existe a necessidade de caracterizar a própria natureza 
das disciplinas, para, então, sugerir uma ligação coerente dos conhecimentos que elas produzem.

Dessa forma, a noção mais conhecida de interdisciplinaridade é a interação entre duas ou mais disciplinas para superar a fragmentação do conhecimento, implicando uma troca entre especialistas de vários campos de conhecimento, na discussão de um assunto, na resolução de um problema, com vistas à melhor compreensão da realidade ${ }^{(12)}$.

Daí, surge a Gerontologia como área de conhecimento específico acerca do envelhecimento, na qual, dentre as várias disciplinas que nela atuam, está a Enfermagem, que interage e articula com outras áreas a comunicação de idéias até a integração recíproca de conceitos formuladores de um determinado conhecimento, bem como a organização da pesquisa e do ensino que com ela podem se relacionar.

A Gerontologia é capaz de recombinar, reconstruir, elaborar a síntese dessas disciplinas do conhecimento, incorporando-lhes aqueles elaborados em sua práxis. Não se trata de redução das ciências a um denominador único, mas à articulação de seus conteúdos, configurando um estatuto coerente e científico acerca do envelhecimento ${ }^{(5)}$.

A interdisciplinaridade tem como característica incorporar os resultados de múltiplas especialidades, formando cada um os seus esquemas conceituais de análise, instrumentos e técnicas metodológicas de assistência, logo, de pesquisa, com uma integração profícua em relação ao idoso. Tal fator fornece a idéia de ligar a teoria à prática gerontológica, não se tratando de conhecer por conhecer, mas de ampliar o conhecimento científico a uma cognição prática, compreendendo-a com possibilidades reais de transformação.

Para tentar trabalhar com o referencial da Interdisciplinaridade (paradigma novo no Brasil), e colocá-lo em prática, criam-se algumas dificuldades, pois não é um trabalho unilateral, mas consta de diversos pensamentos de seus componentes, envolvendo a divisão de poder, de saber e de ouvir a todos. Isso inclui os idosos e, conseqüentemente, seus familiares ${ }^{(13)}$.

Uma estrutura interdisciplinar onde atuam diversos profissionais de saúde possibilita reflexões sobre a forma como se compartilham os conhecimentos para, então, se repensar a maneira pela qual se assiste o cliente idoso, evitando-se atitudes individualistas que nada favorecem o conhecimento acerca da Gerontologia, bem como a assistência a essa clientela.

Existe a necessidade de repensarmos sobre as razões que levam alguns profissionais de saúde a adotarem práticas individualistas sem uma articulação dos saberes que estes produzem. Somente com uma tomada de consciência, de forma harmônica, mais horizontal e recíproca, podemos conduzir a esse objetivo, envolvendo o cliente idoso nesse processo ${ }^{(14)}$.
Com essa afirmação, parto da premissa de que a Enfermagem e as demais áreas que desenvolvem suas atividades voltadas para o envelhecimento, não conseguem explicá-lo como um todo. Explica-se que o seu encerramento epistemológico impõe determinados limites e que a Gerontologia, com o estabelecimento em comum, ou seja, interdisciplinar de suas áreas, favorece 0 preenchimento de lacunas para as dificuldades sociais, psicológicas, físicas e psíquicas do cliente idoso, demandando orientações e fornecendo conhecimentos profissionais, o que era, até então, desconhecido diante de suas especificidades. Com o seu entrelaçamento, viabiliza-se o despertar de um outro olhar que, até então, parecia insólito ${ }^{(5)}$.

A instauração de um novo nível de discurso para a interação entre os profissionais da área de saúde em relação ao cliente idoso caracteriza-se por uma abordagem com novas relações disciplinares, fornecendo caminhos para o conhecimento, reconhecendo-se a interdisciplinaridade como maneira de apreender a sua relação com aspectos da realidade do idoso, como um ideal nunca finalizado na integra, mas com reais possibilidades de orientação para a evolução científica das áreas profissionais que se articulam.

A contribuição da interdisciplinaridade para a Enfermagem advém não só para eliminar barreiras profissionais entre as disciplinas que contribuem para o desenvolvimento de pesquisas, mas também provocam reflexões entre as pessoas que nela atuam, de modo a buscar alternativas para se conhecer mais e melhor o idoso, sem esquecer as diversidades de relações da vida familiar, social, cultural, biológica, entre outras. É um modo de proceder intelectualmente, uma prática de trabalho científico, profissional, de construção coletiva e benéfica para a clientela idosa. Essa visão para a Enfermagem possibilita uma prática organizacional, na qual são estabelecidos saberes, atitudes e valores, tendo como pano de fundo a interdisciplinaridade.

\section{CONCLUSÕES}

No momento, aparecem novos olhares e perspectivas que reconhecem a Gerontologia como uma área rica e cheia de lacunas a serem preenchidas pelas disciplinas que a compõem. Essa compreensão vai além das abordagens convencionais, em relação à clientela idosa, proporcionando novos caminhos de pesquisa para a Enfermagem que, dentre tantas, também está no processo de busca e construção do conhecimento na Gerontologia.

Entender a integração interdisciplinar é passar por um processo reflexivo, consciente, que envolve relações de compromisso entre profissionais de saúde em relação ao cliente idoso e seus familiares, articulando uma finalidade comum do atendimento à saúde, 
na área da Gerontologia.

É relevante enfatizar que, por meio dessa perspectiva, existem várias tentativas de mudança em instituições que visam transcender as dificuldades e aceitar os desafios que a terceira idade nos fornece continuamente. Dessa forma, em comum sintonia, é importante articular as diversas disciplinas (Enfermagem, Nutrição, Medicina, Fisioterapia, Fonoaudiologia, Musicoterapia, Terapeuta Ocupacional, Psicologia, entre outras) numa só maneira de lidar com as transformações políticas, sociais, culturais e econômicas que 0

\section{REFERÊNCIAS BIBLIOGRÁFICAS}

1. Peixoto C. Entre o Estigma e a Compaixão e os Termos Classificatórios: Velho, Velhote, Idosos, Terceira Idade... . In: Moraes MLB, organizadora. Velhice ou Terceira Idade? Rio de Janeiro (RJ): Ed. FGV; 1998. p. 69-84.

2. Debert GG. A Reinvenção da Velhice: Socialização e Processos de Reprivatização do Envelhecimento. São Paulo (SP): Ed. USPFAPESP; 1999.

3. Veras RP. País Jovem de Cabelos Brancos: A Saúde do Idoso no Brasil. Rio de Janeiro (RJ): Relume Dumará - UERJ; 1994.

4. Diogo MJD'E. O Papel da Enfermeira na Reabilitação do Idoso. Rev Latino-am Enfermagem, 2000 janeiro; 8(1):75-81.

5. Sá JLM. Gerontologia e Interdisciplinaridade: Fundamentos Epistemológicos. In: Néri AL, Debert GG, organizadoras. Belice e Sociedade. São Paulo (SP): Papirus; 1999. p. 223-32.

6. Silva J. A Terceira Idade e a Enfermagem: A Construção Histórica de um Projeto em Saúde. [Dissertação]. Rio de Janeiro (RJ): Escola de Enfermagem Anna Nery/UFRJ; 1995.

7. Stucchi D. O Curso da Vida no Contexto da Lógica Empresarial: Juventude, Maturidade e Produtividade na Definição da Préaposentadoria. In: Moraes MLB, organizadora. Velhice ou Terceira Idade? Rio de Janeiro (RJ): Ed. FGV; 1998. p.35-46. país sofre atualmente. Nesse despertar, a interdisciplinaridade serve como um instrumento condutor para a Gerontologia, em busca de mudanças por meio de trabalhos na comunidade e em unidades hospitalares, com resultados que venham a somar conhecimentos e redundar em esforços, no processo de desenvolvimento da área da saúde, com o estabelecimento de diálogos construtivos, em encontros de pesquisas, seminários e reuniões, trabalhando sempre a diversidade, a complexidade e a dinâmica social relacionada, atualmente, ao idoso as quais as ciências tentam explicar.

8. Instituto Brasileiro de Geografia e Estatística. Síntese de Indicadores Sociais: 1999/IBGE, Departamento de População e Indicadores Sociais. Rio de Janeiro (RJ): IBGE; 2000.

9. Debert GG. Antropologia e o Estudo dos Grupos e das Categorias de Idade. In: Moraes MLB, organizadora. Velhice ou Terceira Idade? Rio de Janeiro (RJ): Ed. FGV; 1998. p.49-68.

10. Guareschi PA. Pressupostos Psicossociais da Exclusão: Competitividade e Culpabilização. In: Sawaia B, organizadora. As Artimanhas da Exclusão. Petrópolis (RJ): Vozes; 1999. p.141-56. 11. Santos SMA. Algumas Reflexões Sobre o Ensino de Enfermagem Geronto-Geriátrica na UFSC. Texto e Contexto Enfermagem 1998 janeiro/abril; 8(1):174-85.

12. Weill P, D'ambroso U, Crema R. Rumo a Nova Transdisciplinaridade: Sistemas Abertos de Conhecimento. $3^{\mathrm{a}}$ ed. São Paulo (SP): Summus; 1993.

13. Costa ZS, Figueiredo NMA. (Re)nascer da Terceira Idade: Um Programa para Idosos no HUGG - A Construção de um Espaço. Rev Alternativa de Enfermagem 1998 janeiro; 1(10):20-8.

14. Meirelles BHS, Erdmann AL. A Questão das Disciplinas e da Interdisciplinaridade como Processo Educativo na Área da Saúde. Texto e Contexto Enfermagem 1999 janeiro/abril; 8(1):149-65. 